\title{
Popular Diets: Raw Foods ${ }^{1}$
}

\author{
Alexa Barad, Daniela Rivero-Mendoza, and Wendy Dahl²
}

The raw foods diet has its roots in a vegetarian movement dating back to the 1800s (Leitzmann 2014). As the name implies, a raw foods diet is a dietary pattern composed of mostly or completely raw, unprocessed foods. This publication explores the potential health benefits and risks of a raw foods diet.

\section{What is a raw foods diet?}

A strictly raw foods diet is defined as one in which $90 \%$ or more of food is consumed as raw (Koebnick et al. 2005). A raw foods diet can take many forms. While many raw foods diets are vegan, meaning that they contain no food from animal origin, some are vegetarian and allow dairy and/or eggs, and others are omnivorous and allow raw meat, fish, and poultry. What raw foods diets have in common, however, is that they exclude all foods that have been cooked, pasteurized, or heated above $118^{\circ} \mathrm{F}$ (Cunningham 2004). Instead, raw fruits, vegetables, seeds, nuts, and sprouted grains and beans are consumed. Cold-pressed extra-virgin olive oil and raw virgin coconut oil provide sources of fat. Unpasteurized milk and raw fish, eggs, and meats may be consumed by some individuals following this diet. Food preparation methods include juicing, low-temperature dehydrating, and sprouting. Some preparation methods may be time-intensive and require expensive equipment (e.g., cold-press juicer, high-volume blender, food processor, and dehydrator).

\section{What do the advocates say about the health benefits of the raw foods diet?}

Advocates of raw foods diets claim that raw foods are packed with natural enzymes and nutrients needed for health, and that cooking foods will destroy these enzymes and nutrients (Cunningham 2004). What some may not realize, however, is that we have an abundance of human digestive enzymes to digest carbohydrates, protein, and fat. In addition, the gut microbiota provides a plethora of additional enzymes and thereby ensures that most food residue that escapes digestion will be degraded in the gut, producing health-enhancing substances that provide energy. Plant-sourced enzymes are simply not needed for human digestion and health. Although there is some vitamin loss when foods are exposed to higher temperatures, cooking actually improves the digestibility of many foods, as well as nutrient availability (Carmody and Wrangham 2009).

\section{What are the potential health benefits of a raw foods diet?}

A raw foods diet has been purported to improve health and prevent the development of chronic disease, but there is little, if any, research to support these claims. However, weight loss is possible. This may be in part due to eliminating energy-dense, processed foods with added sugars and fats. Weight loss may also be due to malabsorption of starch and protein. For example, the starch in raw tubers, such as

1. This document is FSHN20-45, one of a series of the Food Science and Human Nutrition Department, UF/IFAS Extension. Original publication date September 2020. Visit the EDIS website at https://edis.ifas.ufl.edu for the currently supported version of this publication.

2. Alexa Barad, former MS-DI student; Daniela Rivero-Mendoza, Extension and research coordinator; and Wendy Dahl, associate professor, Food Science and Human Nutrition Department, UF/IFAS Extension; Gainesville, FL 32611.

The Institute of Food and Agricultural Sciences (IFAS) is an Equal Opportunity Institution authorized to provide research, educational information and other services

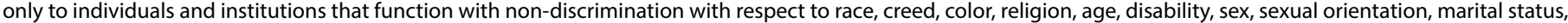

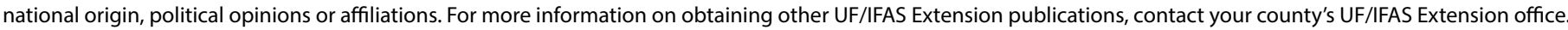
U.S. Department of Agriculture, UF/IFAS Extension Service, University of Florida, IFAS, Florida A \& M University Cooperative Extension Program, and Boards of County Commissioners Cooperating. Nick T. Place, dean for UF/IFAS Extension. 
potatoes, is resistant to digestive enzymes unless cooked. Cooking functions to disperse the starch, allowing enzymes access to the starch for digestion, and hence increases the energy provided from the food (Carmody and Wrangham 2009). Heating also disrupts the structure of proteins, increasing their digestibility by making them more accessible to human enzymes (Carmody and Wrangham 2009). When foods are eaten raw, a significant amount of starch and some of the protein may not be digested, and instead these macronutrients transit the gut to the colon where they are fermented by gut bacteria. Fermentation provides some energy, but fewer calories than digestion. This lower provision of energy may lead to weight loss, and long-term adherence to a raw foods diet may lead to a body weight below a healthy range (Koebnick et al. 1999).

Typically, a raw foods diet is high in fruits and vegetables, and therefore high in fiber, potassium, and certain vitamins. The Dietary Guidelines for Americans promotes intake of a variety of fruits and vegetables, including raw forms (USDA 2015). Not surprisingly, adults consuming a raw foods diet long-term have high plasma $\beta$-carotene concentrations (Garcia et al. 2008), because $\beta$-carotene is abundant in carrots, sweet potatoes, and other vegetables and fruit. In a study of individuals following a diet high in raw vegetables and fruits (1500-1800 g/day), lower LDL (bad) cholesterol and triglyceride concentrations were reported (Koebnick et al. 2005), which, in general, are associated with reduced risk of cardiovascular disease (Grundy et al. 2019). However, lower HDL (good) cholesterol was also reported (Koebnick et al. 2005). It is important to remember that the benefits of high fruit and vegetable intake can be obtained by following less restrictive dietary patterns than a raw foods diet.

\section{What are the risks of a raw foods diet?}

Choosing to consume a raw foods diet poses health risks. Raw foods may carry harmful bacteria that can cause serious, potentially fatal, foodborne illnesses. Raw foods of animal origin, specifically, raw meat, poultry, eggs, shellfish, and unpasteurized milk, are the most likely to be contaminated by harmful microorganisms (CDC 2020). However, fruits and vegetables may also harbor pathogenic microorganisms. Cooking foods can kill pathogens and help to prevent foodborne illness. Poultry and meats should be cooked to a safe internal temperature $\left(145^{\circ} \mathrm{F}-165^{\circ} \mathrm{F}\right.$, which would require an oven temperature of $325^{\circ} \mathrm{F}-450^{\circ} \mathrm{F}$ ) to kill harmful bacteria (CDC 2020). Eggs should be cooked until the yolks and whites are firm (CDC 2020). Unpasteurized milk is not recommended due to the very high risk of contamination by disease-causing microorganisms (CDC 2020). Also, sprouting requires warm, humid conditions, ideal for bacteria to grow. Eating raw or lightly cooked sprouts may lead to foodborne illness (CDC 2020). The Centers for Disease Control and Prevention (CDC) recommends cooking sprouts thoroughly to kill disease-causing microorganisms (CDC 2020). Populations that are at higher risk for foodborne illness include children, pregnant women, older adults, and anyone with a compromised immune system. For more information on food safety, visit https://www.cdc.gov/foodsafety/index.html.

Additionally, some raw foods contain high amounts of compounds called antinutrients. Antinutrients interfere with digestion and absorption of certain nutrients, which can result in deficiencies (Samtiya, Aluko, and Dhewa 2020). For example, raw legumes contain high levels of antinutrients such as lectins, tannins, phenolics, phytate, saponins, and digestive enzyme inhibitors. Some common methods to reduce antinutrients in foods include soaking, cooking, boiling, fermenting, and germinating (Samtiya, Aluko, and Dhewa 2020; Patterson, Curran, and Der 2017). By using methods in combination, such as germinating and boiling, individuals can reduce antinutrients while also preventing foodborne illness.

\section{Summary}

Raw foods diets are restrictive and thus may be challenging to follow long term. Overall, the risks of following a raw food diet outweigh the potential benefits. Most importantly, following this diet may put you at risk of foodborne illness and unintended weight loss. It is recommended that individuals who are currently following or considering following a raw foods diet consult their healthcare provider.

\section{References}

Carmody, R., and R. Wrangham. 2009. "Cooking and the Human Commitment to a High-Quality Diet." Cold Spring Harbor Symposia on Quantitative Biology. 74:427-34. https://doi.org/10.1101/sqb.2009.74.019.

Centers for Disease Control and Prevention (CDC). 2020. "Foods That Can Cause Food Poisoning." https://www.cdc. gov/foodsafety/foods-linked-illness.html [Accessed 24th July 2020].

Cunningham, E. 2004. "What Is a Raw Foods Diet and Are There Any Risks or Benefits Associated with It?" Journal of the American Dietetic Association 104 (10): 1623. https:// doi.org/10.1016/j.jada.2004.08.016h. 
Garcia, A. L., C. Koebnick, P. C. Dagnelie, C. Strassner, I. Elmadfa, N. Katz et al. 2008. "Long-Term Strict Raw Food Diet Is Associated with Favourable Plasma $\beta$-carotene and Low Plasma Lycopene Concentrations in Germans." British Journal of Nutrition. 99 (6): 293-300. https://doi. org/10.1017/S0007114507868486.

Grundy, S. M., N. J. Stone, A. L. Bailey, C. Beam, K. K. Birtcher, R. S. Blumenthal et al. 2019. "2018 AHA/ACC/ AACVPR/AAPA/ABC/ACPM/ADA/AGS/APhA/ASPC/ NLA/PCNA Guideline on the Management of Blood Cholesterol: A Report of the American College of Cardiology/American Heart Association Task Force on Clinical Practice Guidelines." Circulation. 139 (25): e1082-e143. https://doi.org/10.1161/CIR.0000000000000625.

Koebnick, C., A. Garcia, P. Dagnelie, C. Strassner, J. Lindemans, N. Katz et al. 2005. "Long-Term Consumption of a Raw Food Diet Is Associated with Favorable Serum LDL Cholesterol and Triglycerides but Also with Elevated Plasma Homocysteine and Low Serum HDL Cholesterol in Humans." The Journal of Nutrition 135 (10): 2372-8. https:// doi.org/10.1093/jn/135.10.2372.

Koebnick, C., C. Strassner, I. Hoffmann, and C. Leitzmann. 1999. "Consequences of a Long-Term Raw Food Diet on Body Weight and Menstruation: Results of a Questionnaire Survey." Annals of Nutrition and Metabolism. 43 (2): 69-79. https://doi.org/10.1159/000012770.

Leitzmann, C. 2014. "Vegetarian Nutrition: Past, Present, Future." The American Journal of Clinical Nutrition 100 (1): 496S-502S. https://doi.org/10.3945/ajcn.113.071365.

Patterson, C., J. Curran, and T. Der. 2017. "Effect of Processing on Antinutrient Compounds in Pulses." Cereal Chemistry 94 (1): 2-10. https://doi.org/10.1094/ CCHEM-05-16-0144-FI.

Samtiya, M., R. Aluko, and T. Dhewa. 2020. "Plant Food Anti-nutritional Factors and Their Reduction Strategies: An Overview." Food Production, Processing and Nutrition 2:6. https://doi.org/10.1186/s43014-020-0020-5.

United States Department of Agriculture (USDA). 2015. Dietary Guidelines for Americans 2015-2020. https:// health.gov/our-work/food-nutrition/2015-2020-dietaryguidelines/guidelines/ [Accessed 24th July 2020]. 